alternative oral treatment in bronchitis, though again it has no clear advantage in the majority of cases. It is expensive, and while response is often rapid, relapse is not uncommon, even though its effect is bactericidal. Superinfection with yeasts and Pseudomonas occurs with prolonged courses as with other antimicrobials. However, trimethoprim with sulphamethoxazole does have one potential advantage. Nearly all strains of Staphylococcus aureus are sensitive, and staphylococcal pneumonia is the only really life-endangering infective hazard in bronchitis and is particularly common in exacerbations after influenza. Ampicillin and tetracyclines commonly select penicillinase-producing or multiplyresistant staphylococci, and fatal pneumonia may result. This is unlikely to happen when trimethoprim is used. Further, when the distinction between an acute exacerbation and an early pneumonia is not possible, it is worth remembering that staphylococcal pneumonia responds well to trimethoprim with sulphamethoxazole ${ }^{6}$ which can be used to cover either eventuality.

More orthodox treatment for known staphylococcal pneumonia might be fucidin with cloxacillin. However, in vitro antagonism is demonstrable between this pair of drugs, and fucidin with erythromycin is a better combination: it avoids possible interference, there may be synergy of action, and erythromycin is more active than cloxacillin against the pneumococcus. Pneumococcal pneumonia is a common and severe infection in elderly bronchitics, and it is prudent to use the most effective compound in its treatment, so that if the condition is certainly pneumococcal benzyl penicillin is the drug of choice.

Finally, various new drugs have little or no advantage in bronchitis. Cephaloridine is less active than ampicillin against Haemophilus, the minimum inhibitory concentration being 4-8 $\mu \mathrm{g} . / \mathrm{ml}$. as against $0.25 \mu \mathrm{g} . / \mathrm{ml}$. for ampicillin. Since there is a possibility of nephrotoxicity at the higher dose required, cephaloridine is of limited use in this condition. K. M. Citron and J. R. May found no place for rifampicin in bronchitis, and lincomycin and even its 7-chloro-derivative, clindamycin are no more active than erythromycin against Haemophilus species and have nothing to recommend them in this field.

\section{Transmission of Toxoplasmosis}

Toxoplasmosis was first recognized by A. Splendore ${ }^{1}$ in rabbits in São Paulo in 1908. Sixty years later the infection was still present in the same laboratory colony of animals, yet the mode of transmission has remained obscure until very recently. A. Castellani ${ }^{2}$ was probably the first to see the causative organism (Toxoplasma gondii) in man, in 1941 in Ceylon, but the widespread and cosmopolitan nature of the infection was not appreciated until the introduction of the dye test by A. B. Sabin and H. A. Feldman ${ }^{3}$ in 1948. It is now apparent that a large proportion of the world's population are infected-for example, $33 \%$ of adults in England. ${ }^{4}$

1 Turner, G. C., Lancet, 1963, 2, 1292

Schaffner, W., Schreiber, W. M., and Koenig, M. G., New England fournal of Medicine, 1966, 274, 451 .

3 Percival, A., Armstrong, Elizabeth C., and Turner, G. C., Lancet, 1969 1, 998.

4 May, J. R., and Delves, Doreen M., Lancet, 1965, 1, 929.

Hughes, D. T. D., British Medical fournal, 1969, 4, 470

Darrell J. H., Garrod, L. P., and Waterworth, Pamela M., fournal of Clinical Pathology, 1968, 21, 202.

7 Citron, K. M., and May, J. R., Lancet, 1969, 2, 982.
The symptoms of infection are usually negligible. The commonest form of the disease is lymphadenopathy, or Siims's ${ }^{5}$ disease, named after the Danish worker who first drew attention to this clinical picture. Apart from the congenital disease and infections arising from laboratory accidents or from the consumption of raw meat ${ }^{6}$ the origin of the millions of inapparent human infections has been shrouded in mystery. Moreover the systematic position of the organism itself was undecided until recently, though evidence from electron-microscopic studies indicated that Toxoplasma is a sporozoan. ${ }^{7}$ The importance of toxoplasmosis in medical and veterinary medicine was considered by an expert panel of the World Health Organization in 1968 and its technical report has just been issued. ${ }^{8}$ It contains much useful information on the epidemiology and diagnosis of the condition.

In 1965 W. M. Hutchison, ${ }^{9}$ in a small laboratory in Scotland, showed that Toxoplasma could be transmitted by the faeces of cats which had been fed on Toxoplasmainfected mice. At first he thought that the vehicle of transmission was the ovum of the nematode worm, Toxocara cati, but later he and other workers ${ }^{70-13}$ showed that infection could take place in the absence of the nematode. A remarkable feature was the long time (a year or more) during which the faeces remained infectious and also the insusceptibility of the "infective form" to various disinfectants.

Immediately a search was begun in infective faeces for the, as yet, unknown stage of the parasite. The only clues were that it could pass through a $40-50 \mu$ millipore filter and that it was a highly resistant body. The scene then moved to the Statens Seruminstitut of Copenhagen, where the work was continued by a team comprising J. C. Siim, K. Work, and Hutchison. ${ }^{10}$ it It was quickly discovered that small cyst-like structures were present in fairly large numbers in the concentrate prepared from infective faeces. The cysts were oval, measuring $9 \times 14 \mu$, and after some days the contents became divided into two bodies. Four cysts were isolated and from intraperitoneal inoculation into four mice each animal developed a Toxoplasma infection.

1 Splendore, A., Revista da Sociedade Scientifica de São Paulo, 1908, 3, 109.

2 Castellani, A., fournal of Tropical Medicine and Hygiene, 1914, 17, 113.

3 Sabin, A. B., and Feldman, H. A., Science, 1948, 108, 660.

+ Beattie, C. P., in Immunity to Protozoa, ed. P. C. C. Garnham, A. E.

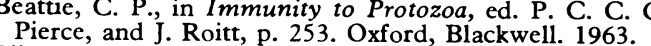

5 Siim, J. C., Annals of the New York Academy of Sciences, 1956, 64, 185

6 Desmonts, G., Couvreur, J., Alison, F., Baudelot, J., Gerbeaux, J., and Lelong, M., Revue Française d'Etudes Cliniques et Biologiques, $1965,10,952$.

Jacobs, L., in Advances in Parasitology, vol. 5, ed. Ben Dawes, p. 1. London, Academic Press. 1967.

8 World Health Organization, Technical Report Series, No. 431, 1969.

9 Hutchison, W. M., Nature, 1965, 206, 961.

10 Hutchison, W. M., Dunachie, J. F., and Work, K., Acta Pathologica et Microbiologica Scandinavica, 1968, 74, 462.

11 Dubey, J. P., fournal of Protozoology, 1967, 14, Suppl. p. 42.

12 Frenkel, J. K., Dubey, J. P., and Miller, N. L., Science, 1969, 164, 432.

13 Sheffield, H. G., and Melton, M. L., Science, 1969, 164, 431.

Work, K., and Hutchison, W. M., Acta Pathologica et Microbiologica Scandinavica, 1969, 75, 191.

5 Siim, J. C., Hutchison, W. M., and Work, K., Acta Pathologica et Microbiologica Scandinavica, 1969, 77, 775 .

16 Hutchison, W. M., Dunachie, J. F., Siim, J. C., and Work, K., British Medical fournal, 1969, 4, 806 .

17 Price, J. H., British Medical fournal, 1969, 4, 141.

18 Doorninck, W. M. van., and Becker, E. R., fournal of Parasitology, 1957, 43, 40. 19 Pulvertaft, R. J. V., Valentine, J. C., and Lane, W. F., Parasitology,

20 Lotze, J. C., Shalkop, W. T., Leek, R. G., and Behin, R., fournal of Parasitology, 1964, 50, 205. 
On section the mature cysts were found to contain two "sporocysts" inside each of which were four "sporozoites." 15 It was difficult to avoid the conclusion that the parasite (which produced toxoplasmosis in mice on inoculation) was a coccidian with an Isospora-like structure. The American workers had reached a similar conclusion as a result of their extensive observations.

The next step was the discovery by Hutchison and colleagues reported briefly in the B.M.F. recently ${ }^{16}$ and more fully this week (page 142), that a typical coccidian lifecycle of schizogony and gametogony occurred in the intestine of germ-free cats which had been fed five to six days earlier on brains containing cysts of Toxoplasma gondii. Development took place in the mucosal cells of the small intestine and culminated in the production of oocysts resembling those present in the faeces.

The suspicion that Toxoplasma belongs to the Sporozoa has thus been verified. The absence of a known sexual stage was the missing link, and now, with the demonstration of gametogony, the 60-year-old problem has been solved. Two important questions remain to be settled: How does man become infected? And what is the significance of the well-known cystic and pseudocystic forms of the parasite? The association with cats has long been known, ${ }^{17}$ and it seems probable that the natural or biological cycle is initiated by the ingestion of the highly infective and resistant oocysts from the excreta of domestic animals. The part played by the cyst and pseudocyst in toxoplasmosis may be entirely aberrant and might possibly be explained by the proliferation of the products of schizogony in abnormal sites. Other coccidian parasites, for example, Eimeria necatrix $^{18}$ are taken up by macrophage cells and are transported in the submucosa of the intestine to the epithelium. Possibly the merozoites of rupturing schizonts of Toxoplasma are similarly absorbed, and instead of remaining in the intestine are taken to different organs, such as lymph nodes, to initiate the proliferative phase and later to the brain and muscle for their final "dead end" as cysts. Such multiplication of Toxoplasma gondii is easy to induce in tissue cultures of macrophages and other cells. ${ }^{19}$ It might be noted that "aberrant" cycles are probably absent in all other forms of coccidia with the possible exception of the metastatic development of Eimeria arloing $i^{20}$ in the lymph nodes of sheep. For this reason it is probably wise to defer regarding Toxoplasma as synonymous with Isospora until further experiments establish the exact relationships. The rare human forms of coccidiosis, due to Isospora belli and $I$. hominis, appear to be clearly distinct from toxoplasmosis, as the dimensions of their respective oocysts are entirely different.

\section{Felty's Syndrome and Rheumatoid Arthritis}

In almost all centres concerned with the study and treatment of rheumatoid arthritis the diagnostic criteria are those laid down by the American Rheumatism Association. ${ }^{1}$ Of the eight features listed, six relate to the joints; the other two refer to the characteristic subcutaneous nodules and to serological tests for rheumatoid factor. A variant of the disease, first described by A. R. Felty ${ }^{2}$ in 1924 , is characterized by splenomegaly, fever, pigmentation, and haemato- logical evidence of hypersplenism-namely, anaemia, leucopenia, and sometimes thrombocytopenia. Lymph-node enlargement may also be conspicuous, and the changes in the serum proteins, particularly a fall in albumin and a rise in $\gamma$-globulin, contribute to the suggestion that some immunological disturbance is causing the condition. Though Felty did no more than describe the original five cases, the association of adult rheumatoid arthritis with splenomegaly and hypersplenism is invariably referred to as Felty's syndrome.

In addition to the positive criteria required to justify a diagnosis of rheumatoid arthritis a number of other conditions more or less commonly associated with arthritis or arthralgia must be excluded. Of these the most likely to be confused with Felty's syndrome is systemic lupus erythematosus, in which arthritis occurs in about two-thirds and splenomegaly in one-third of the cases. The rarity of erosions, the frequency of a positive L.E. cell test, and such other features as the rash, renal lesions, and the course of the disease usually make the differentiation fairly easy.

Though the early reports of Felty's syndrome make little reference to any disease in the liver, later ones refer to various hepatic lesions, notably some diffuse lymphocytic infiltration associated with increased portal fibrosis. As Dr. L. M. Blendis and his colleagues report in the B.M.F., this week (page 131), hepatic disease may well be a major feature of the syndrome, culminating in a fully developed cirrhosis with portal hypertension and oesophageal varices.

All 12 patients they studied had classical or definite rheumatoid arthritis according to the American association's criteria. All were sero-positive and had subcutaneous nodules, and though the L.E. cell test was positive in three the other clinical features and course clearly supported the diagnosis of rheumatoid arthritis against systemic lupus. An interesting feature was the wide variation in time between the onset of the rheumatoid lesions and those of Felty's syndrome, the range being from less than one year to 28 years, with a mean of 12 years. The size of the spleen showed an equally large range from a minimum of $300 \mathrm{~g}$. to a maximum of $1,520 \mathrm{~g}$.

Hypersplenism was shown mainly by leucopenia, the white cell count ranging from 600 to 3,300 per cu. $\mathrm{mm}$. The platelets were less severely affected, ranging from 86,000 to 200,000 per cu. mm., and no patient developed purpura. The anaemia was more apparent than real, because, though the haemoglobin exceeded $12 \mathrm{~g}$. per $100 \mathrm{ml}$. in only two patients and in several was less than $8 \mathrm{~g}$. per $100 \mathrm{ml}$., the total red cell mass was either normal or even slightly above the normal range of $22-34 \mathrm{ml}$. per $\mathrm{kg}$. body weight. The apparent anaemia was the result of expanded plasma volume, which in five patients ranged between 61.8 and $111.0 \mathrm{ml}$. per $\mathrm{kg}$, whereas the normial range is between 34 and $48 \mathrm{ml}$. per kg.

In classical rheumatoid arthritis, when cases with amyloidosis are excluded, there is remarkably little evidence of any hepatic abnormality, anatomical or functional. ${ }^{3}$ It is noteworthy, therefore, that of the 12 cases of Felty's syndrome reported by Blendis and his colleagues eight showed abnormal liver function tests of some kind, and in five some abnormality of the histological structure was

\footnotetext{
1 American Rheumatism Association, Annals of the Rheumatic Diseases, $1959,18,49$.

2 Felty, A. R., Johns Hopkins Hospital Bulletin, 1924, 35, 16.

3 Gardner, D. L., Pathology of the Connective Tissue Diseases, p. 106. London, Arnold. 1965.
} 